\title{
THE CARBON DIOXIDE DISSOCIATION CURVE OF THE BLOOD IN INFANCY AND CHILDHOOD.
}

\author{
BY \\ NOAH MORRIS, M.D., and STANLEY GRAHAM, M.D.
}

(From the Dept. of Pædiatrics, Glasgow University, and Biochemical Dept., Royal Hospital for Sick Children, Glasgow.)

Since 1914 much work has been done on the $\mathrm{CO}_{2}$ dissociation curve in health and disease. So tar, with the exception of a few results published in 1923 by Conway-Verney ${ }^{1}$ all the observations reported have been made on the blood of adults. The work described in this paper deals with the $\mathrm{CO}_{2}$ dissociation curves of the blood of a group of normal children as well as a few with disturbances of acid-base equilibrium.

\section{Methods of Investigation.}

The method employed was essentially the same as that originally described by Christiansen, Douglas and Haldane ${ }^{2}$. For the analysis of the gas-mixtures, Haldane's air-gas analysis apparatus was used, while the Haldane blood-gas apparatus was employed for the blood. The water-bath accessories were slightly modified. Instead of an electric thermostat, a mercury one was used which controlled the temperature to within $0 \cdot 5^{\circ} \mathrm{C}$. quite satisfactorily. The apparatus was designed to hold two saturating flasks at once, so arranged as to revolve about a central axis, in this way obviating the necessity for a fan to keep the temperature constant throughout the bath. An approximately known amount of $\mathrm{CO}_{2}$ was introduced into the saturating flask by means of a graduated burette to the lower end of which was attached a mercury reservoir. The upper end of the burette was fitted with a two-way stop-cock and two arms, one connecting with the reservoir of $\mathrm{CO}_{2}$ and the other for attaching by means of rubber tubing to the saturating flask. After the gases in the flask had become mixed, the pressure in the flask was equalized with atmospheric pressure by a momentary release of the clip on the attached rubber tube.

In all our experiments fully oxygenated venous blood was used. Potassium oxalate and sodium fluoride in minute amounts were used in the syringe, the former to prevent clotting and the latter to prevent possible conversion of glucose into lactic acid, which by combining with base lowers the carbon-dioxide combining capacity of the blood (Lovatt-Evans ${ }^{3}$ ). It has been shown by several investigators that neither of these substances affects the $\mathrm{CO}_{2}$ dissociation curve. The determinations were carried out in all cases within two hours of the withdrawal of the blood.

At least three determinations were made on each sample of blood. In every case the first tension of $\mathrm{CO}_{2}$ to which the blood was exposed was between 35 and $40 \mathrm{~mm}$. $\mathrm{Hg}$. The gas mixture in the flask was then enriched with $\mathrm{CO}_{2}$ so as to produce a tension of over $60 \mathrm{~mm} . \mathrm{Hg}$. Lastly the blood was exposed to a low tension at least below $25 \mathrm{~mm}$. of $\mathrm{CO}_{2}$. Haggard and Henderson ${ }^{4}$ found that exposure of blood to low pressures of $\mathrm{CO}_{2}$ led to an irreversible alteration of the $\mathrm{H}_{2} \mathrm{CO}_{3}$ : $\mathrm{NaHCO}_{3}$ equilibrium. Lovatt-Evans ${ }^{3}$ showed that this change was not necessarily due to low tensions of $\mathrm{CO}_{2}$ but merely that it took place more rapidly under these conditions. It has been shown that blood exposed to a low partial pressure of $\mathrm{CO}_{2}$ undergoes partial hæmolysis. The hæmoglobin thus liberated into the plasma probably acts as a weak acid and hinders the fixation of $\mathrm{CO}_{2}$ by the base, with the result that the amount of $\mathrm{CO}_{2}$ taken up at the various tensions of $\mathrm{CO}_{2}$ is distinctly less in a hæmolysed than in a non-hæmolysed sample. Figure 1 illustrates an experiment which demonstrates the effect of hæmolysis. It will be seen that at a tension of $40 \mathrm{~mm}$. $\mathrm{Hg}$. laked blood takes up abcut 10 rer cent. less $\mathrm{CO}_{2}$ than does unlaked blood. 
As laking is likely to occur at any tension less than $25 \mathrm{~mm}$. $\mathrm{Hg}$., and since the complete sample of blood is put into the saturating flask at the beginning of the experiment, it is desirable that the exposure to low tensions of $\mathrm{CO}_{2}$ should be performed last. Otherwise hæmolysis may occur and vitiate the results.

\section{The Normal Cakbon Dioxide Dissociation Curve.}

In Fig. 2 are plotted the points obtained at various tensions of $\mathrm{CO}_{2}$ from the bloods of ten normal children whose ages varied from three months to ten years. The abscissa, represents the $\mathrm{CO}_{2}$ tension in $\mathrm{mm}$. $\mathrm{Hg}$. at $37 \cdot 5^{\circ} \mathrm{C}$. to which the blood was exposed. The ordinate represents the total amount of $\mathrm{CO}_{2}$ (free and combined) taken up at any particular tension of $\mathrm{CO}_{2}$. Twenty-three points

Fig. I

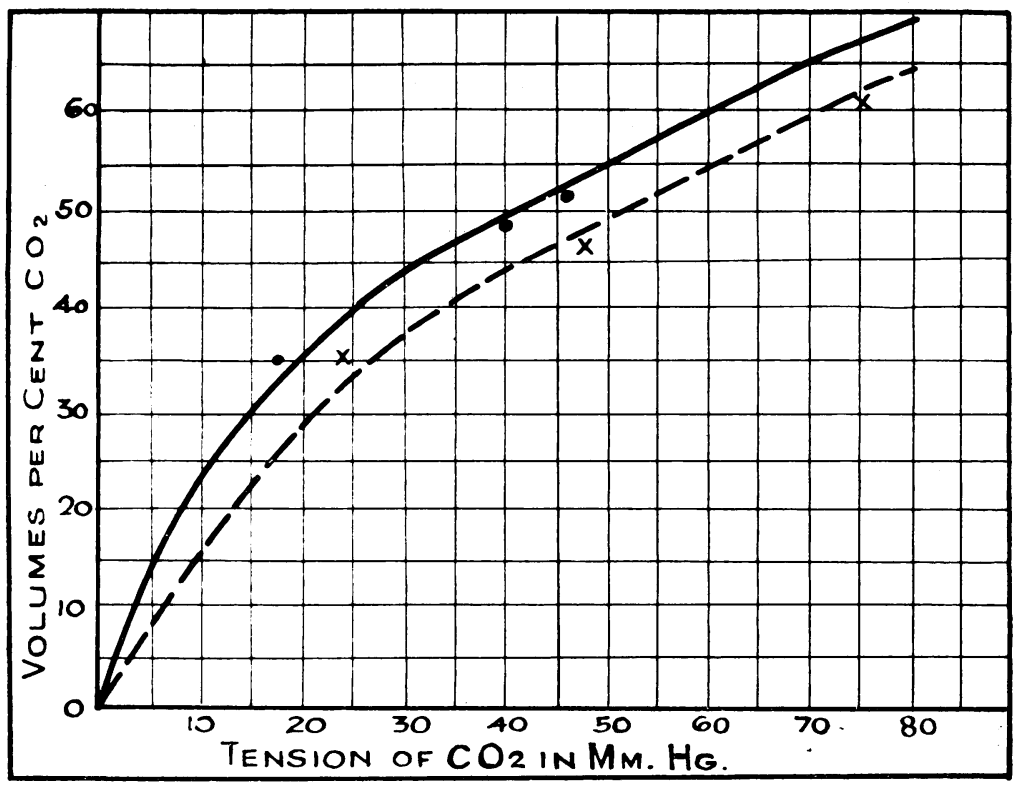

Continnous line and dots $=$ Unlaked blood.

Broken line and crosses = Laked blood.

are marked and with the exception of one point at the low tension of $8 \mathrm{~mm}$. (probably an error) all are within the limits indicated by the dotted lines. At a $\mathrm{CO}_{2}$ tension of $40 \mathrm{~mm}$. $\mathrm{Hg}$., the total $\mathrm{CO}_{2}$ content varied from 47 to 56 volumes per cent. with an average of $\mathbf{5 1 . 5}$ volumes per cent. which falls almost exactly on the curve for normal blood as determined by Christiansen, Douglas and Haldane ${ }^{2}$. It is convenient in describing $\mathrm{CO}_{2}$ dissociation curves to indicate the position of each with reference to that of a standard at a tension of $\mathrm{CO}_{2}$ equivalent to $40 \mathrm{~mm}$. $\mathrm{Hg}$. The standard generally used is the curve given by Haldane's blood which contains 51 volumes per cent. at $40 \mathrm{~mm}$. $\mathrm{Hg}$. tension of $\mathrm{CO}_{2}$. If a curve shows 56 volumes per cent at this tension, this will be indicated by saying that it is $9 \cdot 8$ per cent. $\frac{56-51}{51} \times 100$ above the standard. The limits for our series of normals would thus be -8.9 to $+9 \cdot 8$. In other words, 
if the blood absorbs more $\mathrm{CO}_{2}$ than normal, the curve is shifted to the left and may be spoken of as hypercapnic. If the blood absorbs less CO, than normal, it is shifted to the right and is therefore hypocapnic.

Peters, Barr and Rule ${ }^{5}$ analysed the $\mathrm{CO}_{2}$ dissociation curves in a series of normal adults, in all 18, 3 of their own and 15 collected from the literature. At a tension of $40 \mathrm{~mm}$. $\mathrm{Hg}$., they define the limits of normal as being from 43 to 56 vol. per cent. with an average of 49 vol. per cent., or in terms of Haldane's curve, $-\mathbf{1 5 \cdot 6}$ per cent to $+9 \cdot 8$ per cent. In children in whom there is generally found evidence of a more unstable acid-base equilibrium, one might have expected that the limits of normal would at least have been wider than in

FI(i. II

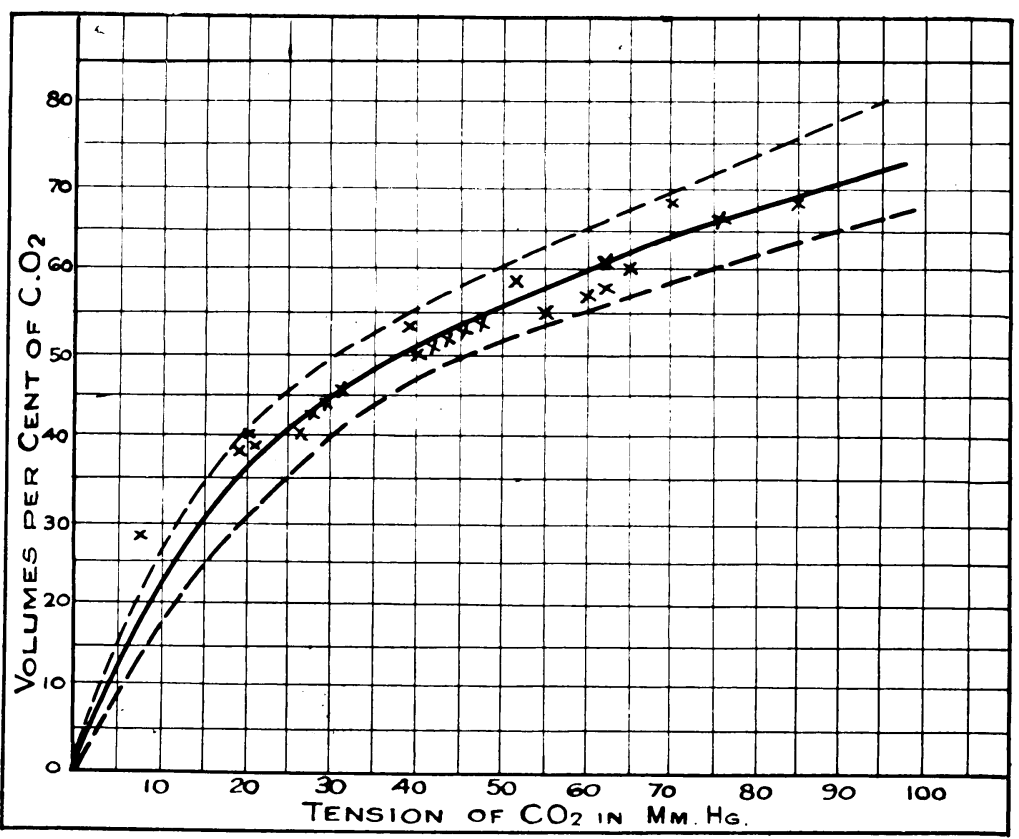

adults. Such, however, was not our experience in this series. Straub, Meier and Schagintweit ${ }^{6}$ found that there was a greater variation in the $\mathrm{CO}_{2}$ dissociation curves in Germany during the hunger years 1917 to 1919 than in 1921, and they attributed this directly to the poor nutritional conditions leading to an unstable acid-base equilibrium.

\section{Significance and Discussion of Abnormal Curves.}

It must be emphasized at this point that the direction of the deviation of the curve from the normal does not determine whether there is a state of acidosis or alkalosis. An increase in the $\mathrm{CO}_{2}$ capacity may be due to a primary decrease in the non-gaseous acid radicles such as $\mathrm{Cl}, \mathrm{PO}_{4}$, etc. (non-gaseous alkalosis), or to an increase in the $\mathrm{CO}_{2}$ which has led to a secondary migration of these nongaseous acid radicles (gaseous acidosis). Similarly a decrease in the capacity 
of the blood to hold $\mathrm{CO}_{2}$ may be due either to a primary increase in the nongaseous acid radicles (non-gaseous acidosis), or to a primary decrease in the $\mathrm{CO}_{2}$ (gaseous alkalosis). Thus, by itself, a $\mathrm{CO}_{2}$ dissociation curve does not give any more information about the $p H$ of the blood than can be determined by a single determination of its total $\mathrm{CO}_{2}$ content. If, however, in addition to the dissociation curve, the total $\mathrm{CO}_{2}$ content of the arterial blood be known, a figure representing the $\mathrm{pH}$ of that sample of blood can readily be ascertained. For example, the $\mathrm{CO}_{2}$ dissociation curve of a sample of blood is as shown in Fig 3 (normal curve). The total $\mathrm{CO}_{2}$ content of the arterial blood in this case was 45 vol. per cent.

Fic: III.

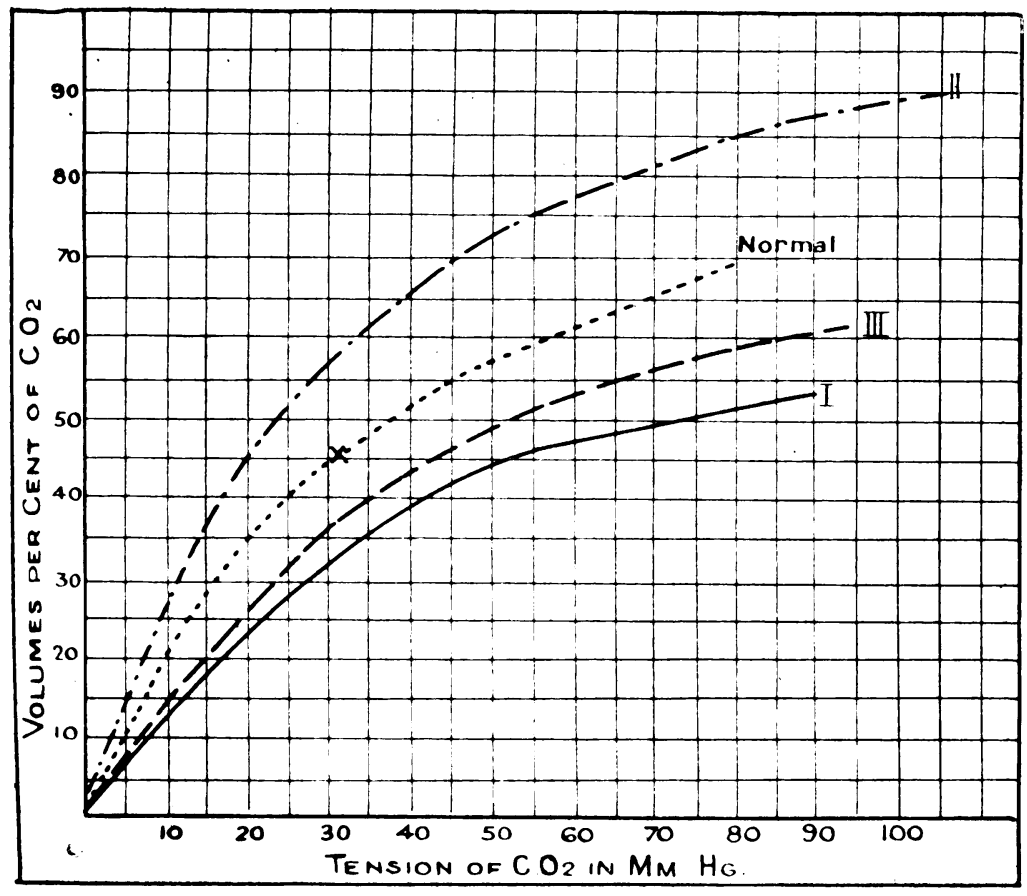

I Salicylate poisoning.

Il Pyloric stenosis.

III Lobar pneumonia.

Therefore the rension of $\mathrm{CO}_{2}$ necessary to enable the blood to take up 45 vol. of $\mathrm{CO}_{2}$ is $31 \mathrm{~mm}$. Hg. This point marked $\mathrm{x}$ on the graph (Fig. 3) is known as the arterial point. By means of Bohr's coefficient of solubility for $\mathrm{CO}_{2}$ in whole blood $(0.51)$, the tension is equivalent to 2.08 vol. per cent., which represents the free $\mathrm{CO}_{2}$ content of the blood. The combined $\mathrm{CO}_{2}$ is then 42.92 vol. per cent. $(45 \cdot 0-2 \cdot 08)$. Hasselbalch's formula $\mathrm{pH}=\mathrm{pk}_{\mathrm{r}}+\log \frac{\left[\mathrm{BHCO}_{3}\right]}{\left[\mathrm{HCO}_{3}\right]}$ $\mathrm{pk}_{\mathrm{I}}$ being a constant equal to $6 \cdot 1$ - can now be used to determine the $\mathrm{pH}$, which is thus equal to $6 \cdot 1+\log \frac{42 \cdot 92}{2 \cdot 08}$, i.e., $7 \cdot 415$. 
It is still under discussion whether the dissociation curve determined from fully oxygenated venous blood gives a correct picture of the cunditions in arterial blood. Acid substances are produced by the tissues especially during work, and lower the $\mathrm{CO}_{2}$ combining capacity of the blood. These acid substances, however, are not given off in the lungs but are carried over into the arterial system. Eppinger and Schiller i have shown that the $\mathrm{CO}_{2}$ curves of arterial and venous blood differ but little, such differences as there are being well within the limits of experimental error, but Fraser, Graham and Hilton ${ }^{8}$ maintain that such is not the case in the majority of cases. It must be admitted that in disease, where there may be pathological conditions such as a marked relative increase in the corpuscular volume of venous blood, the $\mathrm{CO}_{2}$ curves of arterial and venous bloods may show marked differences.

If the total $\mathrm{CO}_{2}$ content of the blood has been determined from a venous sample there will be introduced an error in the determination of the $\mathrm{pH}$ owing to the fact that venous blood contains 2 to 4 volumes of $\mathrm{CO}_{2}$ more than the arterial, the exact amount depending roughly on the degree of venosity. The figure derived from the venous $\mathrm{CO}_{2}$ and the dissociation curve indicates the $\mathrm{pH}$ neither of the arterial nor of the venous blood. To obtain the venous $\mathrm{pH}$ it would be necessary to construst a $\mathrm{CO}_{2}$ dissociation curve at the tension of oxygen which is present in the venous blood. Despite this error the figure obtained by using the $\mathrm{CO}_{2}$ content of the venous blood and the $\mathrm{CO}_{2}$ dissociation curve of fully oxygenated blood does yield a figure which is of some value in assessing the state of the acid-base balance.

The curves obtained from the bloods of three children suffering from conditions in which it appeared probable that there was some disturbance in acid-base balance are given in Fig. 3 .

Curve I was obtained from the blood of a child suffering from salicylate poisoning. The curve is shifted to the right of normal and is thus hypocapnic. This might be due either to the over-production of acid substances such as occurs in diabetic coma with the consequent diminution in the available alkali (non-gaseous acidosis), or to the over-stimulation of the respiratory centre with washing-out of the $\mathrm{CO}_{2}$ by over-breathing (gaseous alkalosis). The total $\mathrm{CO}_{2}$ content of the venous blood was $32 \cdot 4$ vol. per cent.; by using this figure in conjunction with the dissociation curve (admittedly an inaccurate method for reasons already given) we find that the $\mathrm{pH}$ is $7 \cdot 28$ which is to the acid side of normality.

Curve II was obtained from the blood of an infant with congenital pyloric stenosis. It is to the left of normal (hypercapnic). This might be due either to a diminution of the acid radicles (non-gaseous alkalosis), or to depression of the respiratory centre with decreased output of $\mathrm{CO}_{2}$ (gaseous acidosis). The volume of breathing would be diminished in both conditions. In the first instance (non-gaseous alkalosis), the combined $\mathrm{CO}_{2}$ is primarily increased and the breathing would be diminished in an effort to keep the free $\mathrm{CO}_{2}$ as high as possible and so cause a minimal disturbance to the normal $\mathrm{HCO}_{3}: \mathrm{BHCO}_{3}$ ratio of $1: 20$. In the case of the gaseous acidosis, the primary change is in the free $\mathrm{CO}_{2}$ which is conserved because of the diminished sensitivity of the 
respiratory centre by some poison or toxin (morphine). The combined $\mathrm{CO}_{2}$ is secondarily raised in order to keep the ratio as zonstant as possible. The work of other investigators as well as some unpublished work of our own shows that in pyloric stenosis, the $\mathrm{pH}$ of the blood is frequently on the alkaline side of normality. This indicates that the hypercapnic nature of the $\mathrm{CO}_{2}$ dissociation curve in this condition is due to a diminution of the acid radicles, that is, a non-gaseous alkalosis. It must be emphasized that such a conclusion is not justified by a consideration of the dissociation curve alone.

Curve III is the curve obtained from the venous blood of a boy on the fourth day of a lobar pneumonia. The curve is hypocapnic and the total $\mathrm{CO}_{2}$ content of the venous blood was slightly diminished, namely $43 \cdot 3 \mathrm{vol}$. per cent. On the curve the $\mathrm{CO}_{2}$ tension at this volume of $\mathrm{CO}_{2}$ is $40 \mathrm{~mm}$. $\mathrm{Hg}$. which is the equivalent of a free $\mathrm{CO}_{2}$ content of $2 \cdot 69$ vol. per cent. The combined $\mathrm{CO}_{2}$ would then be $40 \cdot 61$ vol. per cent., and by applying Hasselbalch's formula, the venous $\mathrm{pH}$ works out at $\mathbf{7 \cdot 2 7}$. As this patient was seven years old, it was possible to obtain the figure for the free $\mathrm{CO}_{2}$ in another way, namely by the analysis of air equilibrated with the arterial blood in the rectum. By this method the tension of $\mathrm{CO}_{2}$ was found to be $37.7 \mathrm{~mm}$. $\mathrm{Hg}$. the equivalent of $2 \cdot 53 \mathrm{vol}$. per cent. Employing this figure, the combined $\mathrm{CO}_{2}$ would be $40 \cdot 77$ vol. per cent., and the $\mathrm{pH} 7 \cdot 29$ which is more accurate than the venous $\mathrm{pH}$ of 7.27. It is of interest to note that on the curve at a tension of $37.7 \mathrm{~mm}$. $\mathrm{Hg}$., the total $\mathrm{CO}_{2}$ is 42 vol. per cent., whereas that determined in the venous blood was $43 \cdot 3$ vol. per cent.

These figures suggest a mild degree of non-gaseous acidosis. One must, however, be cautious about drawing conclusions. Oxygen desaturation of varying degree is always present in lobar pneumonia and must be taken into account in a consideration of the state of the acid-base balance. Meakins and Davies ${ }^{9}$ believe that the condition usually present in lobar pneumonia is a partially compensated gaseous alkalosis. Such a condition would of course, also shift the $\mathrm{CO}_{2}$ dissociation curve to the right, i.e., render it hypocapnic and sause a diminution in the total $\mathrm{CO}_{2}$ content as occurred in this case. At the same time lobar pneumonia is usually associated with a markedly acid urine and an increase in the excretion of ammonia. There is a retention of chlorine, which is not, however, evidenced by a high blood chloride content. In addition an increase in some unknown organis acid radicle has been reported in the blood. All these facts tend to support the view that the condition is an acidosis. On the other hand Binger, Hastings and Neill ${ }^{10}$ have reported a case in which the administration of sodium bicarbonate had a distinctly harmful effect by producing a marked alkali excess in the blood, although the urine remained acid throughout. Another factor of importance is the anoxamia which per se induces an alkalosis. Many years ago, Bohr, Hasselbalch and Krogh ${ }^{11}$ demonstrated that lowered tensions of $\mathrm{CO}_{2}$ caused the oxyhæmoglobin dissociation curve to shift to the left, that is to hold on more firmly to its oxygen. It is difficult, therefore, to reconcile the association of the diminished oxygen saturation with a condition of alkalosis. It must be admitted that the question is one of extreme complexity, and it cannot be finally decided from the findings so far obtained. 


\section{Conclustons.}

1. The limits of the $\mathrm{CC}_{2}$ dissociation curves obtained from the bloods of ten normal children at $40 \mathrm{~mm}$. $\mathrm{Hg}$. are from 47 to 56 vol. per cent. $(-8 \cdot 0$ to $+9 \cdot 8$ per cent).

2. Haggard and Henderson's observations on the occurrence of hæmolysis at low tension with consequent reduction in the $\mathrm{CO}_{2}$ combining capacity are confirmed.

3. The $\mathrm{CO}_{2}$ dissociation curve in one case of pneumonia and one case of salicylate poisoning is shown to be hypocapnic and in one example of pyloric stenosis to be hypercapnic. The significance of these findings with reference to acid-base equilibrium is briefly discussed.

We desire to express our thanks to the Medical Research Council by whom the expenses of this work were defrayed.

\section{REFERENCES.}

1. Conway-Verney, R., Brit. Med. Jour., London, 1923, ii, 866.

2. Christiansen, J., Douglas, C. G., \& Haldane, J. S., J. of Phys., Lond., 1914, XLVIII, 244.

3. Lovatt-Evans, C., J. of Phys., Lond., 1922, LVI, 146.

4. Haggard, H. W., \& Henderson, Y., J. Biol. Chem., N.Y., 1922, LIV, 149.

5. Peters, J. P., Barr, D. P., \& Rule, F. D., J. Biol. Chem., N.Y., 1921, XLV, 489.

6. Straub, H., Meier, Kl., \& Schagintweit, E., Zeit.f. d. ges. exp. Med., Berlin, 1923, XXXII, 229.

7. Eppinger, H., \& Schiller, W., Wien Arch.f. kl. Med., Vienna, 1921, II, 3.

8. Fraser, F. R., Graham, G., \& Hilton, R., J. of Phys., Lond, 1924, LIX, 221.

9. Meakins, J. C., \& Davies, H. W., Respiratory Function in Disease, Edinburgh, 1925, 238.

10. Binger, C. A. L., Hastings, A. B., \& Neill, J. M., Arch. Int. Med., Chic., 1923, XXXI, 145.

11. Bohr, C., Hasselbalch, K. A., \& Krogh, A., Skandinav. Arch. f. Physiol., Berlin \& Leipzig, 1907, XVI. 412. 